\title{
The Relationship Between Physical Activity and Mental Satisfaction in American College Students
}

\author{
Minhyun Kim ${ }^{1, ~ *, ~ K i b u m ~ C h o ², ~ H e e s u ~ L e e ~}{ }^{3}$, Ilsuk Sun ${ }^{4}$ \\ ${ }^{1}$ Health Exercise Sports and Science, University of New Mexico, Albuquerque, USA \\ ${ }^{2}$ College of Physical Activity and Sport Sciences, West Virginia University, Morgan Town, USA \\ ${ }^{3}$ Department of Physical Education \& Athletic Training, University of South Carolina, Columbia, USA \\ ${ }^{4}$ Department of Logistics, Jangan University, Suwon, South Korea
}

Email address:

mhkim@unm.edu (M. Kim)

\section{To cite this article:}

Minhyun Kim, Kibum Cho, Heesu Lee, Ilsuk Sun. The Relationship Between Physical Activity and Mental Satisfaction in American College Students. American Journal of Sports Science. Vol. 3, No. 5, 2015, pp. 85-88. doi: 10.11648/j.ajss.20150305.11

\begin{abstract}
The main purpose of this study was to examine the relationship between college students' regular physical life and mental satisfaction specifically regarding loneliness and depression happiness and rest and, comfort satisfaction. 238 college students were surveyed for this study, employing Godin Leisure Time-Exercise Questionnaire (GLTEQ), and General WellBeing Schedule (GWB) to obtain data. Regressions analyses revealed significant relationships between physical activity and two variables. The result of regression analysis for happiness and satisfaction factor was statistically significant $(\mathrm{F}=145.434$, $\left.\mathrm{p}=.000, \mathrm{R}^{2}=0.414\right)$. Additionally, another regression analysis for rest and comfort factor was statistically significant $(\mathrm{F}=$ $\left.103.393, \mathrm{p}=.000, \mathrm{R}^{2}=0.334\right)$. The study results contain meaningful implications for college students suggesting that doing regular physical activity is vital as it promotes their physical and psychological well-being.
\end{abstract}

Keywords: Physical Activity, Mental Satisfaction, American College Students

\section{Introduction}

The benefits of physical activity have been well documented. Regular physical activity has a variety of important consequences [1]. They include reducing risk factors for cardiovascular diseases for people of all ages and decreasing psychological problems, such as depression, anxiety, and stress [2]. Furthermore, physical activity has positive impacts on reducing serious diseases, including diabetes and cancer [3]. In addition to physical and psychological benefits, physical activity has a positive impact on developing social relationships [4] as well as enhancing perceptions of self-mastery and self-efficacy [5]. In short, engaging in various regular physical activities can enhance individuals' quality of life [6].

In fact, it is recommended that in order for adolescent and college students to maintain proper health, they should be required to engage in moderate to vigorous exercise, such as cardiorespiratory fitness (e.g., swimming, jogging, bicycling, and basketball) three or more days per week for more than 20 minutes per occasion [6]. However, despite the importance of physical activity, extensive research has found that the amount of physical activity time among college students has declined [7, 8]. For example, a study revealed that approximately $40 \%$ to $50 \%$ of college students do not take part in any physical activity [9]. This results in an increasing prevalence of obesity and overweight and psychological ills, such as anxiety, depression, and worries. A study revealed that the level of college students' participation in physical activity is closely correlated to their levels of participation in their adult lives [10]. Thus, it is imperative for college students to realize the value of physical activity and to take part in it regularly.

Research has found that regular physical activity increases life satisfaction $[11,12,13]$. Life satisfaction is defined as "the degree to which an individual judges the overall quality of his life-as-a-whole favourably." (p.10) [14]. Life satisfaction is one of the apparent quality of life indicators; there is no one key to life satisfaction, but a number of factors contribute to daily life satisfaction such as personality traits [15], socio-economic status, and relationships [14]. Given that many factors are associated with life satisfaction, mental health has an important effect on life satisfaction [16]. College students experience mental stress due the transitional nature of their lives, such as 
being independent, facing financial pressure, achieving academic credits, and concerns about the future [17]. Thirteen percent of American college students showed an anxiety disorder [18], but they did not seek proper treatment resources [19]. If college students are unable to cope with stress effectively, it results in increasing feelings of loneliness, nervousness, and anxiety [20]. One of the critical ingredients of promoting life satisfaction is an active lifestyle [21]. In particular, among college students and adolescents, physical activity might be considered to have long-term benefits and to play a significant positive difference on one's emotional state and mental satisfaction. In fact, in contrast to a wealth of research on the mental satisfaction of adults in general [22], most research has explored small, rather specific groups, such as children and youth; a scarce number of studies have been conducted on specific college populations. Thus, there is a need to examine college student populations to clarify the mental satisfaction benefits of physical activity. To summarize, the purpose of this study was to investigate the relationship between different levels of physical activity and psychological satisfaction among college students.

\section{Methodology}

This study was conducted as a quantitative research. The researchers measured the effects of physical activity performance levels of American college students on their mental satisfaction.

\subsection{Instruments}

In this research, multiple questionnaires were employed: demographic questions about gender and age, Godin Leisure Time-Exercise Question (GLTEQ), and General Well-Being Schedule (GWB) developed by Godin. The GLTEQ, is commonly used to assess an individual's present stage of exercise behavior [23]. The GLTEQ is an effective measurement because there are only four self-reported questions based on recall self-report in a typical week in terms of physical activity time (e.g., how many times per week) and the intensity (e.g., low, moderate and high). The GLTES (Godin Leisure Time-Exercise Scale) can be calculated by (9 $\times$ Vigorous $)+(5 \times$ Moderate $)+(3 \times$ Light $)$. Based on the GLTES, three levels of physical activity were categorized. The three categorized groups were analyzed as low, moderate, and high activity levels. The GWB questions sought a daily life satisfaction and were designed as a 6 point Likert-scale. It consists of randomly assigned positive and negative questions about their daily life satisfaction so as to alleviate effects of acquiescence. The positive questions indicate that a low score represents high satisfaction whereas the negative questions contain as a small part of entire questions indicates that a high score represents a high satisfaction. The number of the items on GWB is 20 , and they consist of three types that ask about then mental satisfaction of one's daily life during the previous month.

\subsection{Participants}

The 238 participants for this study were college students at universities in California. The participants represented various majors and ages.

\subsection{Data Analyses}

Questionnaires were sent to 240 students, and 238 were returned. This study employed factor analysis and Cronbach's alpha to verify the validity and reliability of the data on the questionnaire. A regression analysis was conducted to verify the effect of the level of physical performances on daily mental satisfaction.

\section{Results}

\subsection{Demographic Characteristics}

Descriptive statistics for demographic characteristics are shown in Table 1. Among the 238 participants, $41.8 \%(n=99)$ were men, and $58.2 \%(\mathrm{n}=139)$ were women. Among the participants, $15.6 \%(\mathrm{n}=15)$ were freshmen, $14.6 \%(\mathrm{n}=14)$ were sophomores, $25 \%(\mathrm{n}=24)$ were juniors, and $44.8 \%(\mathrm{n}$ $=43$ ) were seniors.

Table 1. Descriptive Analysis.

\begin{tabular}{|c|c|c|c|}
\hline \multirow{3}{*}{ Demographics } & \multicolumn{2}{|l|}{ Gender } & \multirow{2}{*}{$\begin{array}{l}\text { Total } \\
n=238(100.0 \%)\end{array}$} \\
\hline & $\begin{array}{l}\text { Male } \\
n=99(41.8 \%)\end{array}$ & $\begin{array}{l}\text { Female } n=139 \\
(58.2 \%)\end{array}$ & \\
\hline & M (SD) & M (SD) & M (SD) \\
\hline $\begin{array}{l}\text { Age in Years } \\
\text { Year in College }\end{array}$ & $23.7 \pm 5.64$ & $22.8 \pm 4.64$ & $23.14 \pm 5.09$ \\
\hline Freshmen & $15(15.6 \%)$ & $23(16.8 \%)$ & $38(16.0 \%)$ \\
\hline Sophomore & $14(14.6 \%)$ & $23(16.8 \%)$ & $37(15.6 \%)$ \\
\hline Junior & $24(25.0 \%)$ & $41(29.9 \%)$ & $65(27.4 \%)$ \\
\hline Senior & $43(44.8 \%)$ & $50(36.5 \%)$ & $93(41.0 \%)$ \\
\hline
\end{tabular}

$\mathrm{M}=$ mean; $\mathrm{SD}=$ standard deviation

\subsection{Validity and Reliability}

In this study, an exploratory factor analysis was conducted to remove items that construct validity was obstructed by the result and to check the construct validity of GWB. Internal consistency of the scales was measured by Cronbach's alpha and is shown in Table 2. The alpha values higher than 0.70 were considered as appropriate reliability [24]. Cronbach's alpha values were $0.928,0.914$, and 0.877 , which meant the satisfactory consistency in all factors.

Table 2. Results of Exploratory Factor Analysis of GWB.

\begin{tabular}{lll}
\hline Variables & & Cronbach's a \\
\hline \multirow{3}{*}{ Daily Satisfaction } & loneliness and depression & .928 \\
& happiness and satisfaction & .914 \\
& rest and comfort & .877 \\
\hline
\end{tabular}

\subsection{Effects of Regular Physical Activity on Daily Satisfaction}

The regression analysis was employed to determine the effects of regular physical activity on mental satisfaction. 
Three factors of daily satisfaction were used as a dependent variable, and the GLTES was used as an independent variable. Table 7 showed the regression analyses for the dependent variables, loneliness and depression, happiness and satisfaction, and rest and comfort for GLTES. The result of the first regression analysis for loneliness and depression factor was not significant $\left(F=76.044, p=.000, R^{2}=0.270\right)$. The result of the second regression analysis for happiness and satisfaction factor was statistical significant $(\mathrm{F}=145.434$, $\left.\mathrm{p}=.000, \mathrm{R}^{2}=0.414\right)$. This result showed that college students with a high frequency of physical activity feel more happiness and satisfaction. The result of the third regression analysis for the rest and comfort factor was statistically significant $\left(\mathrm{F}=103.393, \mathrm{p}=.000, \mathrm{R}^{2}=0.334\right)$. This result revealed that college students who are being physically active feel more rest and comfort.

Table 3. Results of Regression for the Effects of Regular Physical Activity on Mental Satisfaction.

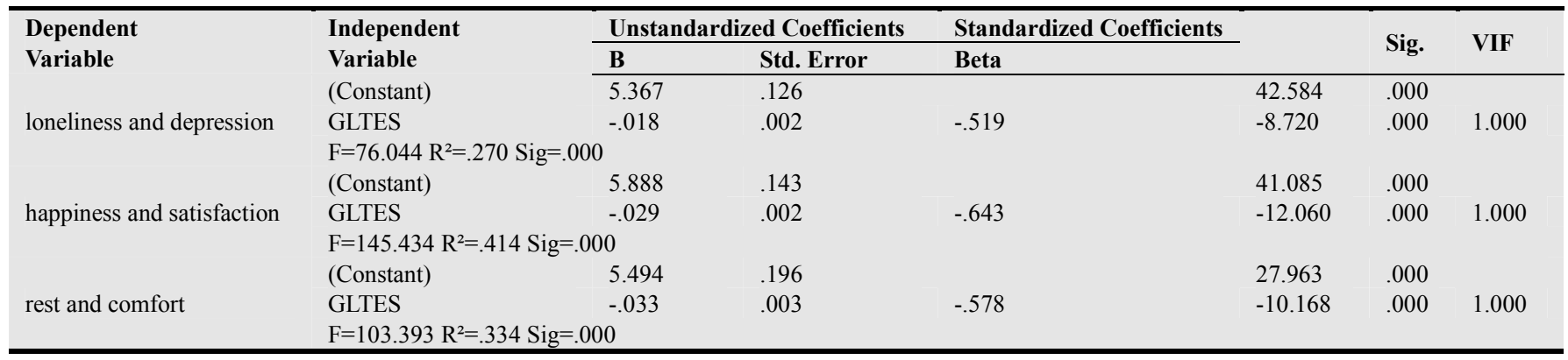

\section{Limitations}

This study is limited to generalizing its results to apply the whole college students because the study was conducted by sampling college students in California. In addition, this study is limited because it does not encompass all factors of daily life satisfaction because the GWB that examines psychological aspects does not consider social and environmental satisfaction for daily life. In the future, studies that are more varied will be required to examine diverse social classes beyond American college students.

\section{Discussion and Conclusion}

This study examined the effects of regular physical activity on college students' daily life satisfaction. Mental satisfaction is as important as physical health. Mental wellbeing includes various factors, emotional stability, positive feelings, and a relaxed mind. Although numerous studies already have examined the relationship between the levels of physical activity and mental satisfaction, this study is unique in investigating the relationship between regular physical activity and specific states of mental satisfaction, such as loneliness and depression, happiness and satisfaction, and rest and comfort by studying American college students. The study results extended the understanding of the relationship between physical activity and mental satisfaction in college students. Based on this study, happiness and satisfaction were among the variables that were most highly linked with regular physical activity. The possible reason is that physical activity has positive impacts on individual mood and emotional state [25]. For instance, a study has shown that physically active people show positive emotions, including excitement, enthusiasm, and happiness [26]; 10-15 minutes of vigorous walking can help enhance individual mood states [27]. Additionally, as physical activity has a positive impact on improving selfesteem and self-confidence [28], it may help influence overall mental satisfaction. In fact, when people are physically active, acquiring new skills, and accomplishing physical tasks, the possibility of increased self-esteem is greater.

According to this study, another significant contribution of physical activity is that it helps individuals to become emotionally relaxed and calm. Results of this study are similar to other studies' results of those who are physically less active are more likely to experience mental health diseases, such as depression and anxiety [7, 12]. In fact, many college students experience different levels and types of anxiety and stress due to academic work, peer relationships, and concerns about the future. This stress can directly influence of the feelings of constant worry and depression. However, this study showed the positive relationship between physical activity and the individual's rest and comfort. It is obvious that physical activity is beneficial in greatly reducing and preventing one's anxiety and stress level [29].

In conclusion, although many factors contribute to mental satisfaction, this study showed strong evidence of the positive relationship between regular physical activity and mental satisfaction among college students. This study's findings underscore the importance of regular physical activity and sustaining such activity as a life habit. College students live in a critical moment of a lifetime in terms of their physical and psychological health that will carry into their future lives. Thus, college students should be able to see the significant value of taking part in regular physical activity, and therefore seek the best opportunity to take part in such activities to promote their physical and psychological well-being. College students should find any physical activities that they can continue to enjoy and perform to increase the level of physical activity. Physical activity can be a simple potential medicine for college 
students to attain physical and mental wellness.

\section{References}

[1] Zullig KJ, Valois RF, Huebner ES, Drane JW. Adolescent health-related quality of life and perceived satisfaction with life. Quality of Life Research 2005; 14: 1573-1584.

[2] Lollgen H, Bockenhoff A, Knapp G. Physical activity and allcause mortality: an updated meta-analysis with different intensity categories. International Journal of Sports Medicine $2009 ; 30: 213-224$.

[3] Fontaine K, Barofsky I. Obesity and health-related quality of life. Obesity Reviews 2001; 2: 173-182.

[4] McAuley E, Konopack JF, Motl RW, Morris KS, Doerksen SE, Rosengren KR. Physical activity and quality of life in older adults: Influence of health status and self-efficacy. Annals of Behavioral Medicine 2006; 31: 99-103.

[5] Stewart LK, Flynn MG, Campbell WW, Craig BA, Robinson JP, Timmerman KL, McFarlin BK, Coen PM, Talbert E. The influence of exercise training on inflammatory cytokines and C-reactive protein. Medicine and Science in Sports and Exercise 2007; 39:1714-1719.

[6] United States Department of Health and Human Services (1998). Healthy People 2010: Physical Activity and Fitness.

[7] Keating XD, Guan J, Castro J, Bridges, DM. A mental analysis of college student physical activity levels. Journal of American College Health 2005; 64: 116-215.

[8] McArthur LH, Raedeke TD. Race and sex differences in college student physical activity correlates. American Journal of Health Behavior 2009; 33: 80-90.

[9] Ferrara CM. The college experience: Physical activity, nutrition, and implications for intervention and future research. Journal of Exercise Physiology Online 2009; 12: 23-35.

[10] Racette SB, Deusinger SS, Strube MJ, Highstein GR, Deusinger RH. Weight changes, exercise, and dietary patterns during freshman and sophomore years of college. Journal of American College Health 2005; 53: 245-251.

[11] Arent SM, Landers DM, Etnier JL. The effects of exercise on mood in older adults: A meta-analytic review. Journal of Aging and Physical Activity 2000; 8: 407-430.

[12] Craft L. Exercise and clinical depression: Examining two psychological mechanisms, Psychology of Sport and Exercise 2005; 6: 151-171.

[13] Penedo FJ, Dahn JR. Exercise and well-being: A review of mental and physical health benefits associated with physical activity. Current Opinion in Psychiatry 2005; 18: 189-193.

[14] Veenhoven R. Questions on happiness: classical topics, modern answers, blind spots in subjective well-being: an interdisciplinary approach, Great Britain: Pergamon Press. $1991 ; 7-26$.
[15] Gray JA. Brain systems that mediate both emotion and cognition. Cognition \& Emotion 1990; 4: 269-288.

[16] Viren S, Tomas CP, Dhachayani S, Thambu M, Kumaraswami K, Debbi S, Adrian F. General health mediates the relationship between loneliness, life satisfaction and depression: A study with Malaysian medical students. Journal Social Psychiatry and Psychiatric Epidemiology 2007; 42: 161-166.

[17] D'Zurilla TJ, Sheedy CF. Relation between social problemsolving ability and subsequent level of psychological stress in college students. Journal of Personality and Social Psychology 1991; 61: 841-846.

[18] American College Health Association. The American College Health Association. Journal of American College Health 2009; 57: 477-488.

[19] Suvisaari J, Aalto-Setälä T, Tuulio-Henriksson A, Härkänen T, Saarni S, Perälä J. Mental disorders in young adulthood. Psychological medicine 2008; 39: 287-299.

[20] Wright JJ. Reported personal stress sources and adjustment of entering freshmen. Journal of counseling psychology 1967; 14: 371-373.

[21] Wyshak G. Women's college physical activity and self-reports of physician-diagnosed depression and of current symptoms of psychiatric distress. Journal of Women's Health GenderBased Medicine 2001; 10: 363-37.

[22] Smale B, Dupuis S. The relationship between leisure activity participation and psychological well-being across the lifespan. Journal of Applied Recreation Research 1993; 18: 281-300.

[23] Godin G, Shephard J. Godin Leisure-Time Exercise Questionnaire. Medicine and Science in Sports and Exercise 1997; 29:36-38.

[24] Hair JF, Anderson RE, Tatham RL, Black WC. Multivariate Data Analysis, (5th Edition). 1998. Upper Saddle River, NJ: Prentice Hall.

[25] Kanning M, Schlicht W. Be Active and Become Happy: An Ecological Momentary Assessment of Physical Activity and Mood. Journal of Sport \& Exercise Psychology 2010; 32: 253-261.

[26] Pasco JA, Jacka FN, Williams LJ, Brennan SL, Leslie E, Berk M. Don't worry, be active: positive affect and habitual physical activity. Australian and New Zealand Journal of Psychiatry 2011; 45: 1047-1052.

[27] Ekkekakis P, Hall EE, VanLanduyt LM, Petruzzello SJ. Walking in (affective) circles: Can short walks enhance affect? Journal of Behavioral Medicine 2000; 23: 245-275.

[28] Fox KR. Let's get physical. In: Fox KR, editor. The physical self: from motivation to well-being. 1997; Leeds: Human Kinetics.

[29] Conn VS. Anxiety outcomes after physical activity interventions: meta-analysis findings. Nursing Research 2010; 59: 224-31 